\title{
Cross Cultural Variations in Corporate Social Responsibility
}

\author{
* Maqsood Hayat, Assistant Professor \\ ** Shehzad Khan, Assistant Professor (Corresponding Author) \\ *** Muhammad Faizan Malik, Assistant Professor
}

\begin{abstract}
The aim of this study is to examine the fundamental factors that affect the understanding level of corporate social responsibility (CSR) across South Asian countries. CSR was measured by seven dimensions defined by ISO26000 and number of other indicators (e.g., education, religion, region) were employed to figure out cross-cultural impact. This research unveiled the basic but general trends about the concept of CSR. Majority of the respondents prioritized accountability, transparency and respect for stakeholder interests. Overall trends regarding every CSR dimension are leaded by master students and followed by doctoral students. On average scale, the followers of all the 3 leading religions (Buddhism, Hinduism and slam) in the region have similar inclination towards CSR concept; however, Christianity shows incomparable results. Bhutan is the only country where most educated people (PhD students) has given less importance to CSR actions as compare to other students' groups. Overall, this study explores no perceptible discrepancies in the trends and pattern of CSR within South Asian region. This research presents the ground level understandings from the potential workforce (students) about the widespread concept of CSR. These results affirm the claims that educational institutes and course contents taught in South Asian region are still lagging behind in the race of literacy. Academia should not only upgrade their teaching method but also the course content in order to build the capacity of their potential workforce to resolve any problem in future. The results of this study are also important for international agencies, government and nongovernmental organizations and other relevant institutions to understand the basic 'know how' of customized CSR approach across the countries.
\end{abstract}

Keywords: Corporate Social Responsibility; Corporate Ethics; Students' Perception; South Asia Introduction

Bowen (1953), defined that Corporate Social Responsibility (CSR) is the interaction of corporation and society where business world discharges their obligation to satisfy the broader range of social needs. CSR is basically the nonfinancial corporate efforts to bring social, environmental and governance development not only to sustain business operation but also for the overall stakeholders. Multinational enterprises (MNEs) are facing big challenges in new markets due to the differences in institutions, politics, environmental and cultural systems (Aguilera-Caracuel et al., 2013). CSR concept is supposed to be a technique for corporations to respond the local transitional forces and outlooks to build corporate legitimacy (Deegan and Unerman, 2006; Amran and Haniffa, 2011). Involvement in CSR activities can be a corporate edge, especially when they are competing in developed countries or even in developing world with multinationals enterprises.

Recently, the concept of CSR got more attention in developing countries (Khan et al., 2020). Although many scholars have already explored various CSR's dynamics both in developing and developed world, however, still there is no specific demarcation in definition, approach, framework and application of this concept. In spite of deep research, so far there is neither agreed CSR definition (Blowfield \& Murray, 2008; Lockett, Moon, \& Visser, 2006;), nor any fixed conceptual framework (Carroll, 1999). Guan and Pourjalali (2010), Gray et al. (2015), Han et al. (2010) and Kanagaretnam et al. (2014) found that corporate management practices are affected by domestic culture. Number of studies (e.g., Uddin et al., 2018; Khan et al., 2020) have found a regular influence of the local institutions on CSR in developing countries. This variation in CSR activities and reporting open a new debate to find out the reasons of such variations among different nations and culture. These local

* Yunnan University of Business Management, Kunming, China

** Institute of Business Studies and Leadership, Abdul Wali Khan University Mardan

*** Institute of Business Studies and Leadership, Abdul Wali Khan University Mardan 
dynamics and individual perspectives will lead to more standardized and sophisticated form of domestic CSR. Aguilera-Caracuel et al. (2013) suggested that a customized framework should be introduced for all corporations operating in different countries according to specific economic, legal and cultural systems. Although, it has already been partially recognized and notified in some of developing countries (Sorour et al., 2020) by competing the domestic social, natural and financial issues. However, due to widespread dynamics and complex nature of CSR concept, there is a dreadful need to think beyond the conventional CSR's spheres. Similarly, the execution and enactment of formal ethical parameters don't seem to be appropriate for elaborating the broad theories of CSR. Generally, it is logical to believe that CSR' narrative is dynamic due to discrepancies in local needs and priorities, however, the basic understanding of ethics and doing 'good deeds' remain the same across the nations. In this way, there is possibility that stakeholders from different parts of the world view the broad concept of CSR with different angles. As per the CSR's pyramid (Carroll, 1999), the ethical dimension reflects the social behaviors anticipated by the society irrespective of legal spheres. Whatever the reason, every type of CSR activity build stakeholder's trust and corporate commitment (Hillenbrand et al., 2013). Corporate personnel imitate the overall CSR function of their workplace in personal capacity (El Akremi et al., 2018; Grabner-Kra"uter et al., 2020). More specifically, employees judge and notify firm's CSR actions with their own aspects, rather than from organizational perception ( $\mathrm{Ng}$ et al., 2019). This diversion highlights the execution of CSR than merely expectation, thus, the modified position from corporate managers to policy makers for finding the theoretical and practical essentials. The new era of research literature, which highlights the 'how' and 'why' of CSR, either in individual or corporate capacity, will encounter the new certainties. In this regard, it is very important to find out the 'root cause' of involvement/avoidance of CSR in personal traits (natural) as well as in social and corporate cultures (nursery). As discussed earlier, the concept of CSR is not new, however the basic questions are still not tackled properly. To what extent the social norms and institutional forces resist the 'corporate autocracy'? How can be the social learning process upgraded (manipulated) to propagate the modern issues in future/potential workforce?

Modern problems have compelled academia to revisit the previous policies and develop new techniques to increase social prosperity, corporate performance and technological advancement simultaneously. In this regard, the understanding of students' attitude and behavior about specific phenomenon is important not only to know their current perception for learning purpose but also for policy making about the future endeavor, both in corporate world and academia. Their moral insights will be more helpful to explore new ethical grounds which were unexplored earlier due to generation gap, especially in developing countries context. In short, such process acts as modifier in many contexts, primarily on human characteristics, overall community and thus on CSR specialists and at the organizational level. This research is an attempt to interpret and explain the diverse forces of universal concept (CSR) with the help of individual's perception across various culture. This study will examine whether there is any impact of local culture and institutional forces regarding CSR concept. On the basis of these grounds, it is important to find out the fundamental reasons of the differences about the same concept across the countries. The linkages will be made through culture dynamics and local institutional forces that affect the human perception about the specific phenomenon. This basic nexus will explore the new faces of the existing concept and the essential forces to address the local social needs. Further, this study will build a concreated base which will have both domestic and international flavors (practices) and thus helpful for human development. Fundamentally, this study is forming a triangle by combining the students' knowledge (perception), local institutional dynamics and the broad concept of CSR. The extent of the individual country CSR's level will also be explored by comparing with other sample countries and overall trends in specific region of the study.

\section{Regional and individual CSR's dynamics:}

In remote society, social and economic standards were supposed to be equal; e.g., earning, opportunities, inhabitants, etc., however, the scenario has been changed upside down in modern time. Besides, these parameters have been extended to different individual's inherited traits in addition to complex economic, social and technological standards. As per specific viewpoints, social and economic changes occur within particular terrestrial margins and hence supposed to have a topographical combination. Xiao et al. (2017) stated that there is an organized system composed of all 
the concerned cities, countries and areas, particularly the adjacent regions. Morality or ethics are the set standards in a given society to differentiate 'good' from 'bad'. These ethical standards are laying the foundation for problem solving, decision making and define, regulate and modify the relationship between individuals, organizations and societies (Lages and Fernandes, 2005). Hofstede (1993) proposed that corporate principles reflect the overall mental perception which distinguish organizational characteristics. Purser et al. (1995) proceed with the same theme, proposing that the primary involvement in CSR activities is the result of variation in the degree of individual and corporate's values.

In ethical theories, corporate's moral codes and values are taken as the basis to conduct CSR studies. These theories are categorized into four dynamics: 1 . moral standards; which portray the management decision for executing CSR (Freeman, 2010), 2. universal rights; which includes human rights, labor rights and the environment (United Nations Global Compact, 2015), 3. sustainable development; based on the commitment of preserving resources for the future while meeting current needs (World Commission on Environment and Development, 1987) and the common good; incorporating the communal benefits for conducting CSR operation (Mele, 2002). Whatever theory was tested in CSR research, the dynamics are always based on the interaction between business world and overall society (stakeholders). Generally, corporates principles and other related ethical issues raised due to the interaction between the economic performance and thus social values give birth to rivalry, insecurity of interests which seems unacceptable for both parties. These issues cannot be avoided and even a minute degree of diversion can cause a big damage to corporate reputation and social values. On the other hand, this is not wise decision to portray the image that such avoidance will not cause any dispute among personal, public and corporate interests. In the interaction between government, corporation and society, there are few factors which have griped the balance of power; revolves around the pillars of social equality, economic manipulation, and authority. These factors are essentials for individual's living, satisfaction, feelings and other physiological \& psychological needs. Moreover, these dynamics urge the individual intention to involve in CSR activities (Vveinhardt and Andriukaitiene, 2015). Peterson (2002) stated that corporate environment is affected by rules, regulations, occupational codes, individual's ethics, friendships and social responsibility. Some authors suggest that CSR activities should be initiated from the top management, especially in developing countries (Baba-Abugre, 2014), reflecting their ethical (good deeds) tendencies (Gao and $\mathrm{He}, 2018$ ). Developing countries are more corrupt than developed countries (Hardi and Buti, 2012), South Asia is a developing region and thus supposed to be more corrupt than developed world. Corporate executives and other shareholders have strong bond with the local institutions and thus CSR activities and disclosure are influenced by the political system of the state (Uddin et al., 2018).

In the year 2015, all the countries from the globe sit together with the common agenda of sustainability and launched a foundation with the name of sustainable development goals (SDGs). The aim of SDGs was to provide a suitable living planet not only for the current people but also for the coming generation by the year 2030 (United Nations General Assembly, 2015). Academia having domestic and international linkages, sustainable development goals can advocate a substantial platform with the help of university staff, students, educationist and other stakeholders (Findler et al., 2019). In addition, academia is helpful for laying down the foundation of social equilibrium, and more prosperous world by executing the given standards of sustainability (Findler et al., 2019). "By 2030 ensure all learners acquire knowledge and skills needed to promote sustainable development, including among others through education for sustainable development and sustainable lifestyles, human rights, gender equality, promotion of a culture of peace and non-violence, global citizenship, and appreciation of cultural diversity and of culture's contribution to sustainable development" (United Nations General Assembly, 2015). Managerial and administration personnel in academia have the resources to underscore the internal educational challenges and other external related strategic programs with the involvement of teaching faculty and students. Generally, these institutions, being an active stakeholder, take keen interest in any social, economic, political and religious phenomenon in collaboration with other parties; e.g., government, non-governmental organizations, corporations, civil societies, and overall community. This collaboration and activism can not only bring positive social, economic, legal, political and environmental changes benefits but also earn good reputation for educational institutions. Whatever the techniques are adopted but the students should be kept in center place either in social experiments, learning process, teaching method and policy making. The main 
reason is that this is the students' group who directly expose to any sorts of applied, physical, virtual, formal/informal and societal literacy program.

\section{Impact of social values and learning process on human's perception:}

Institutional theory suggests that social standards of norms, values and other defined rules and regulations have impact on corporate activities (Oliver, 1997). Meyer and Rowan (1977) stated that such institutional forces have visible influence on corporate structure and decisions. Corporations and their stakeholders are dependent on each other's (Suchman, 1995), and the corporate activities are closely analyzed (watchdog) by the stakeholders, especially when they are doing 'bad deeds'. There are number of motives for such watchdog, however, the primary reason is to examine and compensate the crucial lopes.

Without the involvement of human resource, the process of CSR is difficult to implement (Haddock-Millar et al., 2016). To implement CSR practically, corporations should be equipped with the human resources who have the primarily objectives to promote ethical activities (Baba-Abugre, 2014). Giacalone and Thompson (2006) divert the organization-centered world view of CSR to an individual-centric. CSR managers are specialized in specific field and thus has a distinguish job and responsibilities than other managerial staff. They are responsible to formulate and execute CSR strategies to attain everlasting corporate operation. There are less CSR's literature exists at the individual level which has more tendencies towards personal development as compared to human characteristics (Giacalone and Thompson, 2006; Waddock, 2006). These studies emphasize on managers' personal values which are acting as enablers for conducting CSR activities (Schneider et al., 2010). They observed voluntary but heterogeneous pattern of CSR activities and thus reporting. Generally, human nature is more complex, unpredictable and transitional. This is the reason that their likes, dislikes and priorities are subjected to social norms, psychological and biological needs. Human beings are born with various natural characteristics (good \& bad) and thus nourished and developed while interacting in society. As a result, they perform 'good deeds' or 'bad deeds' according to their understanding/perception level. There are many situational factors involved which 'compels' or 'inspires' an individual to perform ethical/unethical activities. Jha and Panda (2017) found that tendencies of doing 'good or bad deeds' are subjected to gender, age, religious affiliation and organizational attachment. Number of studies have agreed that culture can be differentiated on the basis of social standards, religious beliefs, and interactive values which are strictly followed and sustained throughout generation within given context. On this premises, it can be claimed that the people sharing the same cultural values will react similarly to the given object or phenomena. Hofstede (1991) describe "culture is the collective programming of the mind which distinguishes the members of one group or category of people from another", or simply, culture is what almost every members of a certain group have in common and by which they could distinguish themselves from other groups. On contrary, people from diverse cultural circumstances will have dissimilar prospects and social behavior to the same event or situation. As a result of this irregular human's behavior and expectation, the boundaries of different culture drawn across the countries and regions. More specifically, the corporate managers having dissimilar regional and cultural backgrounds will behave differently to CSR's phenomenon or view various CSR's dimensions with different angles, as per their personal social and ethical values. The consideration of cultural and religious values is very crucial in CSR studies (Mehrdost, 2012). As institutional dynamics changes across the countries (Hofstede \& Hofstede, 2001), consequently, moral values, corporate applications, policy execution, and thus CSR practices vary (Van den Heuvel et al., 2014).

Bandura (1971) introduced social learning theory, which states that involvement of any employee in 'good deeds' is the combined effects of personal's behavior (internal/natural) and the corporate environment (external/nursery). As per social learning theory (Bandura, 1971), the top managers are acting as role models for the rest of the personnel who learn standards for reward and punishment (Aryati et al., 2018). Learning process has enabled the human beings to think about themselves and the prosperity of surrounding and future generation. One of the great philosophers (Aristotle) anticipated that sympathy (intrinsic value) can be developed through practices within individuals. Human beings having multi psychological layers to react to various events based on culture, region, religion, sex, peer groups, social class and organizational affiliation (Hofstede et al., 2010). As a result, it is very important to provide a homogeneous environment where all the human beings think and act freely, rather than judging the existing phenomenon on the premises of pre- 
defined standards. Sapolsky (2017), a human biologist states that involvement in ethical behavior is a natural process which is neither controlled by a heart nor cortex but it's a long-term social learning process which then become implicit and automatic. Particularly to CSR's concept, Osagie et al. (2016) introduced eight human characteristics which are helpful in the execution CSR activities in any corporation. These included anticipating CSR challenges; understanding CSR-relevant systems and subsystems; understanding CSR-relevant standards; CSR management competencies; realizing CSRsupportive interpersonal processes; employing CSR-supportive personal characteristics and affective attributes in CSR contexts and personal value-driven competencies; and reflecting on personal CSR views and experiences.

Academia have already recognized the importance of ethical and sustainable course contents in their degree programs. By doing so, the education quality will enhance and will lead to positive corporate culture (Lozano, 2006; Savageau, 2013). Higher education is supposed to be important pillar for national development; which provides human capital equipped with all required skills and knowledge. Likewise, encouragement and inspiration can lead students to achieve high academic goals. De Guimarães et al. (2019) found that motivated students have more inclination to take part in various learning process. There are two types of motivation; controlled and autonomous motivation (Ryan and Deci, 2000b). They further explained that controlled motivation is an individual's characteristics to react to peripheral stimuli, such as commenting on peer's discussion board postings to earn a mark for participation; while autonomous motivation is dependent on other principles and desires.

Globally, the relationship between the academia and CSR is rare (Mehta, 2011), especially in developing countries (Gomez, 2014; Mehta, 2011) which is needed to be explored. From the literature review, it is reflected that most of the scholars have emphasized on executing CSR practices and courses (compulsory) in academia (Watson, 2003). In 2007, United Nations, under the UN umbrella, The Principles for Responsible Management Education (PRME), has urged the academia to equip the students for handling the potential problems (Alcatraz, 2010; Godemann et al., 2014). In this study, the target countries are developing countries and unfortunately education systems in these countries are very slow in the race for chasing the 'milestone' set by the developed countries. From the literature review, it is easy to conclude that the concentration of CSR studies is found in sub-continent and Sri Lanka which mainly revolves around economy, politics, cultural and other institutional forces.

\section{Methodology:}

Various dimensions have been implemented in business and management studies by different scholars to explain the diverse landscape of non-market strategies: i.e., business ethics (Chakrabarty and Bass, 2015), corporate governance (Bondy et al., 2008), sustainability (Brandi, 2017), philanthropy (Mithani, 2017) and business and human rights (Wettstein, 2010). This study has applied descriptive research technique with the help of questionnaire to examine the understanding and level of CSR among the students in South Asia. Number of other researchers (e.g., Stechemesser K. Guenther E., 2012; Hahn et al, 2015) have also used the same method in their CSR's studies. At first, a Pilot survey was conducted among international students (South Asian) studying in China to find out the problems and ambiguity in questionnaire. In this way, the identified gaps were removed and as a result the questionnaire was revised for better interpretation of the respondents. The final survey consists of three parts. The first part was general information about the student (e.g., name, country/region and age); next part about educational background, level and religious affiliation; and the final section about their CSR's awareness and attitude, which mainly consist of seven dimensions.

Total 1,128 questionnaires were disbursed in target region with the help of international students from concerned countries. As a result, 353 questionnaires $(31.30 \%)$ were received in which 34 were rejected due to incomplete information. Thus 319 respondents $(28.30 \%)$ were included during a time period of around 7 months (April 2020 till October 2020). Initially, this study included eight south Asian countries, however questionnaires were not responded in Afghanistan and Maldives, therefore these two countries were excluded from the survey. Details about the questionnaires disbursement and the respondents are shown in table 1.

Table 1. Survey disbursement \& response

\begin{tabular}{llllllll}
\hline & India & Pakistan & Bangladesh & Sri Lanka & Bhutan & Nepal & Total \\
\hline Disbursed & 326 & 238 & 192 & 169 & 91 & 112 & 1128 \\
Respond & 86 & 72 & 57 & 51 & 23 & 30 & 319 \\
\% ratio & 26.40 & 30.25 & 29.70 & 30.20 & 25.30 & 26.80 & 28.30 \\
\hline
\end{tabular}


The main reasons behind the selection of South Asian region are due to huge population, multi-religions, developing economies and were British colonies in past. In this way, the results of the study can be applied to other countries having identical characteristics (e.g., Social, economic and political). The information about the respondents is given in table 2 .

Table 2. Sample demography

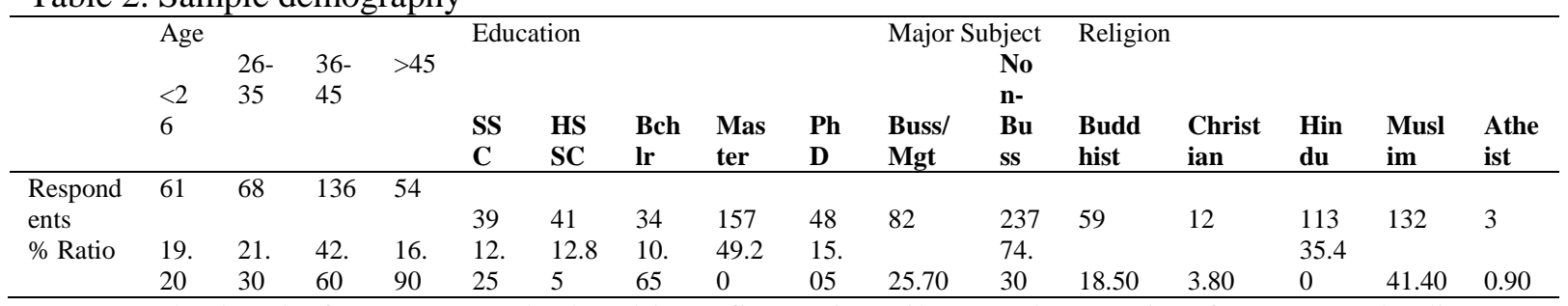

The level of CSR was calculated by a five-point Likert scale (ranging from strongly disagree to strongly agree) with the help of 7 dynamics defined by ISO 26000. These dimensions of ISO 26000 are revolving around the economic, social, environmental, legal, cultural, political, organizational diversity and international norms of behavior. This study will further use seven CSR's terms Accountability (Accb), Transparency (Transp), Ethical behavior (Eth beh), Respect for stakeholder interest (Resp4stak), Respect for rule of law (Resp4RL), Respect for international norms of behavior (Resp4Intl) and Respect for human rights (Resp4HR). In addition, strongly disagree (1), disagree (2), neither agree nor disagree (3), agree (4) and strongly agree (5).

\section{Analysis \& Discussion:}

Business world takes significant steps through various CSR activities to execute the practical actions to manipulate the stakeholders' observations. In this way, all the corporate decisions, especially CSR related strategy should be formulated in such a way to satisfy the demands of all stakeholders up to maximum level and has room for amendment if any query raised from any group in the future. The results of the study have been explained in next sections.

\section{Overall and Region-wise CSR's understanding on Likert scale}

Table 3 shows overall CSR rating (seven dimensions) on the basis of Likert scale within six South Asian countries. The trends in the participants response are almost the same for all the seven dimensions for scale- 1 which shows that overall, only $0.55 \%$ of respondents have shown consent of 'strongly disagreed' for the mentioned CSR dimensions. For the scale-2 (disagreed), on average 5.9\% of the respondents have shown their consent. Large number of students have shown consent for scale3 (neither agree nor disagree) and scale-4 (agree) with average values of $36.10 \%$ and $38.30 \%$ respectively. Similarly, $19.15 \%$ of the respondents have used the 'strongly agree' option with the help of scale-5. In other words, $74.40 \%$ of the students have selected scale- 3 and scale- 4 during the survey. From table 3, it can be concluded that $43.90 \%, 41.10 \%, 42 \%, 39.20 \%$ of the respondents are agreed to involve in accountability, transparency, respect for stakeholder interests and respect for rule of law respectively. Similarly, $37.60 \%, 38.90 \%$ and $39.85 \%$ of the respondents have selected scale-3 (neither agree nor disagree) against ethical behavior, respect for international norms and respect for human rights dimensions respectively.

Table 3. Overall regional CSR's pattern

\begin{tabular}{lccccc}
\hline & $\mathbf{1}$ & $\mathbf{2}$ & $\mathbf{3}$ & $\mathbf{4}$ & $\mathbf{5}$ \\
\hline Accb & 0.95 & 5.60 & 29.15 & 43.90 & 20.40 \\
Transp & 0.00 & 4.10 & 35.70 & 41.10 & 19.10 \\
Eth beh & 0.95 & 5.30 & 37.60 & 35.70 & 20.45 \\
Resp4stak & 0.30 & 5.30 & 35.20 & 42.00 & 17.20 \\
Resp4RL & 0.30 & 6.25 & 36.35 & 39.20 & 17.90 \\
Resp4intl & 0.60 & 5.60 & 38.90 & 32.60 & 22.30 \\
Resp4HR & 0.60 & 9.10 & 39.85 & 33.85 & 16.60 \\
\hline
\end{tabular}

Regarding individual country, table 4 shows the CSR dimensions for all the six countries against the Likert scale (ranging from 1 to 5). As mentioned above, the tendencies of the majority of respondents' perception and understanding restricted to scale-3 and scale-4. Indian respondents have prioritized accountability, respect for stakeholders' interest and respect for rule of law on scale-4 with percentile values of 51.1, 51.2 and 37.2 respectively. Other dimensions like, transparency, ethical behavior, respect for international norms and respect for human rights were prioritized on scale- 3 with percentile values of $46.5,43.0,40.70$ and 45.30 respectively. None of the respondents have used 
scale-1 for any dimensions except respect for international norms with a minor percentage value of 1.20. The trends of prioritizing CSR' dimensions remained almost the same in Pakistan and Bangladesh. Respondents from both of these countries have lined up accountability, transparency, ethical behavior, respect for stakeholders' interests and respect for rule of law on scale-4 and thus respect for international norms and respect for human rights on scale-3. This result confirms the similar tendencies of cultural and religious values on moral actions and particularly CSR in this case. These two countries used to be one till 1971; thus, having the same culture, institutions and also tied by same religious bond. Sri Lankan students have prioritized all the CSR's dimensions on scale-4 except rule of law which has been lined up $35.30 \%$ by scale-3. Respondents from Bhutan have selected accountability, transparency, respect for stakeholders' interests and respect for rule of law on scale-3 with values of $43.50 \%, 39.10,39.20 \%$ and $52.20 \%$ respectively; which shows that most of these students have shown 'neither agree nor disagree' option during their survey. Similarly, ethical behavior and respect for human rights were prioritized on scale-4 with percentage values of 39.1 and 39.2 respectively. Accountability, respect for stakeholders' interests, respect for rule of law and respect for human rights were selected on scale- 4 by Nepalian students with values of $40 \%, 50 \%$, $40 \%$ and $40 \%$ respectively. On the other hands, transparency, ethical behavior and respect for international norms were prioritized on scale- 3 with percentage values of $43.30 \%, 50 \%$ and $40 \%$ respectively.

Table 4. Regional CSR's trends

\begin{tabular}{|c|c|c|c|c|c|c|c|c|c|c|c|c|c|c|c|c|c|c|c|c|c|c|c|c|c|c|c|c|c|c|c|}
\hline & \multicolumn{5}{|c|}{ India } & \multicolumn{5}{|c|}{ Pakistan } & \multicolumn{6}{|c|}{ Bangladesh } & \multicolumn{5}{|c|}{ Sri Lanka } & \multicolumn{5}{|c|}{ Bhutan } & \multicolumn{5}{|c|}{ Nepal } \\
\hline & 1 & 2 & 3 & 4 & 5 & 1 & & 3 & 4 & 5 & 1 & & 3 & & 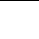 & & 1 & & 3 & 4 & & 1 & & 3 & 4 & 5 & 1 & 2 & 3 & 4 & \\
\hline Accb & 0.0 & 3.5 & 29.1 & 51.1 & 16.3 & 2.8 & 2.8 & 25.0 & 47.2 & 22.2 & 1.8 & 7.0 & 26. & 43 & & 21.1 & 0.0 & 3.9 & 29.4 & 39.3 & 27.5 & 0.0 & 13.1 & 43.5 & 21.8 & 21.7 & 0.0 & 13.3 & 33.4 & 40.0 & 13.4 \\
\hline Transp & 0.0 & 4.7 & 46.5 & 37.3 & 11.6 & 0.0 & 6.9 & 26.4 & 44.5 & 22.3 & 0.0 & 0.0 & 31. & 43 & & 24.6 & 0.0 & 3.9 & 29.5 & 47.1 & 19.6 & 0.0 & 0.0 & 39.1 & 34.8 & 26.1 & 0.0 & 6.7 & 43.3 & 33.3 & 16.7 \\
\hline Eth beh & 0.0 & 3.5 & 43.0 & 34.9 & 18.6 & 1.4 & 6.9 & 32.0 & 36.2 & 23.6 & 1.8 & 7.0 & 38. & 38 & & 14.1 & 2.0 & 7.8 & 29.4 & 35.4 & 25.5 & 0.0 & 4.4 & 34.8 & 39.1 & 21.8 & 0.0 & 0.0 & 50.0 & 30.0 & 20.0 \\
\hline Resp4stak & 0.0 & 3.5 & 31.4 & 51.2 & 13.9 & 0.0 & 6.9 & 38.9 & 38.9 & 15.3 & 0.0 & 5.3 & 33. & 42 & & 19.3 & 2.0 & 7.9 & 33.4 & 33.3 & 23.6 & 0.0 & 4.3 & 39.2 & 26.1 & 30.5 & 0.0 & 3.3 & 40.0 & 50.0 & 6.7 \\
\hline Resp4RL & 0.0 & 9.3 & 34.9 & 37.2 & 18.6 & 0.0 & 4.2 & 38.9 & 43.0 & 13.9 & 0.0 & 5.3 & 33. & 43 & & 17.5 & 0.0 & 5.9 & 37.3 & 35.3 & 21.6 & 4.4 & 4.3 & 52.2 & 30.4 & 8.8 & 0.0 & 6.7 & 26.7 & 40.0 & 26.7 \\
\hline Resp4intl & 1.2 & 5.8 & 40.7 & 25.6 & 26.7 & 1.4 & 6.9 & 38.9 & 37.5 & 15.3 & 0.0 & 5.3 & 42. & 31 & & 21.1 & 0.0 & 2.0 & 37.3 & 41.2 & 19.6 & 0.0 & 13.1 & 26.1 & 30.4 & 30.5 & 0.0 & 3.3 & 40.0 & 30.0 & 26.7 \\
\hline Resp4HR & 0.0 & 10.5 & 45.3 & 29.1 & 15.1 & 1.4 & 7.0 & 43.1 & 30.6 & 18.1 & 0.0 & 7.1 & 42. & 33 & & 17.6 & 2.0 & 5.9 & 33.4 & 41.2 & 17.6 & 0.0 & 21.7 & 34.8 & 39.2 & 4.4 & 0.0 & 10.0 & 26.7 & 40.0 & 23.3 \\
\hline
\end{tabular}

Education-wise CSR's understanding on Likert scale

Table 5 shows the trends of CSR's dimensions on the basis of educational level in South Asian region. It is reflected that overall tendencies of the given CSR's dimensions are revolving around scale-3 and scale- 4 in all educational level except for $\mathrm{PhD}$ where the trends have been diverted to scale-5 in addition to scale-3 and scale-4. As expected, students with SSC educational background have selected visible trends in favor of scale-1 which shows that these groups have not more knowledge about the importance of CSR activities. Similarly, students with upper educational levels (ranging from HSSC to PhD) did not show or just a minute tendency (only master) for being on scale1. Generally, it is perceived, that course contents are more updated and miscellaneous in higher educational institutes (universities); however, not even a slight change were observed among universities and non-universities students except $\mathrm{PhD}$ in this study. There is an assumption that usually $\mathrm{PhD}$ students have also corporate experience and are more practical due to their age as compared to bachelors and master students. Therefore, it might be the reason that $\mathrm{PhD}$ students might have encountered CSR concept during their workplace instead of learning in academia. This result affirms the claims that educational institutes and course contents taught in South Asian region are still lagging behind in the race of literacy.

Table 5. CSR's trends on the basis of educational level

\begin{tabular}{|c|c|c|c|c|c|c|c|c|c|c|c|c|c|c|c|c|c|c|c|c|c|c|c|c|c|}
\hline & \multicolumn{5}{|c|}{ SSC } & \multicolumn{5}{|c|}{ HSSC } & \multicolumn{5}{|c|}{ Bachelor } & \multicolumn{5}{|c|}{ Master } & \multicolumn{5}{|c|}{ PhD } \\
\hline \multirow{4}{*}{ Accb } & 1 & 2 & 3 & 4 & 5 & 1 & 2 & 3 & 4 & 5 & 1 & 2 & 3 & 4 & 5 & 1 & 2 & 3 & 4 & 5 & 1 & 2 & 3 & 4 & 5 \\
\hline & 7 & 2 & 3 & 3 & 5 & 0 & ? & 6 & 2 & & 0 & 8 & 2 & 3 & 2 & 0 & 3 & 2 & 5 & 2 & 0 & 0 & 1 & 4 & 3 \\
\hline & & 3. & 0. & 3. & 3. & 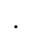 & 2. & 1. & 9. & 3 & . & . & 6. & 8. & 6. & . & 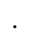 & 4. & 2. & 0 . & . & . & 8. & 1. & 9. \\
\hline & 7 & 1 & 8 & 4 & & 0 & & 0 & 3 & & 0 & 8 & 5 & 2 & 5 & 0 & 2 & 2 & 2 & 4 & 0 & 0 & 7 & 7 & 6 \\
\hline Tran & 0 & 1 & 4 & 2 & 7. & 0 & 4. & 3 & 4 & 1 & 0 & 0 & 4 & 4 & 1 & 0 & 1 & 4 & 3 & 2 & 0 & 2 & 1 & 5 & 2 \\
\hline & & 8. & 6. & 8. & 7 & 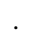 & 9 & 1. & 6. & 7. & . & 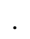 & 1. & 4. & 4. & 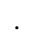 & . & 0 . & 6. & 0 . & . & . & 0 . & 8 . & 9. \\
\hline
\end{tabular}




\begin{tabular}{|c|c|c|c|c|c|c|c|c|c|c|c|c|c|c|c|c|c|c|c|c|c|c|c|c|c|}
\hline \multirow{4}{*}{$\begin{array}{l}\text { Eth } \\
\text { beh }\end{array}$} & 0 & 0 & 2 & 2 & & 0 & & 7 & 3 & 1 & 0 & 0 & 2 & 1 & 7 & 0 & 9 & 8 & 9 & 4 & 0 & 1 & 4 & 4 & 2 \\
\hline & 7 & 1 & 3 & 2 & 1 & 0 & 1 & 3 & 2 & 2 & 0 & 0 & 3 & 4 & 2 & 0 & 2 & 4 & 4 & 1 & 0 & 0 & 3 & 2 & 3 \\
\hline & . & 8. & 3. & 8. & 2. & . & 4. & 1. & 9. & 4. & . & . & 5. & 1. & 3. & . & . & 0. & 0. & 6. & . & 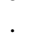 & 7. & 9. & 3. \\
\hline & 7 & 0 & 3 & 3 & 8 & 0 & 6 & 7 & 3 & 4 & 0 & 0 & 3 & 2 & 5 & 0 & 6 & 8 & 2 & 6 & 0 & 0 & 5 & 2 & 3 \\
\hline Resp & 2 & 7 & 4 & 3 & 7 & 0 & 9 & 2 & 4 & 1 & 0 & 8 & 4 & 3 & & 0 & 4 & 3 & 4 & 1 & 0 & 0 & 2 & 3 & 3 \\
\hline 4sta & . & 7. & 6. & 5. & 7. & . & 9. & 2. & 8. & 9. & . & . & 4. & 8. & 8. & . & . & 6. & 3. & 6. & 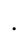 & 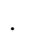 & 7. & 9. & 3. \\
\hline $\mathbf{k}$ & 6 & & 1 & 9 & & 0 & 8 & 0 & 8 & 5 & 0 & 8 & 2 & 2 & 8 & 0 & 5 & 3 & 3 & 0 & 0 & 0 & 1 & 6 & 3 \\
\hline Resn & 2 & 2 & 3 & 2 & & 0 & 1 & 2 & 4 & 1 & 0 & 5 & 3 & 4 & 1 & 0 & 0 & 3 & 4 & 1 & 0 & 4 & 3 & 3 & 2 \\
\hline 4RL & . & 5. & 8. & 5. & 7 & . & 2. & 6. & 1. & 9. & . & . & 8. & 1. & 4. & . & . & 8. & 2. & 7. & & & 3. & 5. & 7. \\
\hline & 6 & 7 & 5 & 6 & & 0 & 2 & 8 & 5 & 5 & 0 & 9 & 2 & 2 & 7 & 0 & 6 & 9 & 8 & 8 & 0 & 2 & 3 & 4 & 1 \\
\hline Resn & 5 & 3 & 3 & 2 & 5. & 0 & 4 & 4 & 3 & 1 & 0 & 5 & 3 & 4 & 2 & 0 & 1 & 3 & 3 & 2 & 0 & 0 & 3 & 3 & 2 \\
\hline $\begin{array}{l}\text { Kesp } \\
\text { 4intt }\end{array}$ & . & 0. & 5. & 3. & J. & . & $\begin{array}{l}4 . \\
9\end{array}$ & 3. & 4. & 7. & . & . & 2. & 1. & 0. & . & . & 9. & 3. & 6. & & & 9. & 1. & 9. \\
\hline & 1 & 8 & 9 & 1 & & 0 & 9 & 9 & 1 & 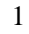 & 0 & 9 & 3 & 2 & 6 & 0 & 3 & 5 & 1 & 1 & 0 & 0 & 6 & 2 & 2 \\
\hline Resn & 2 & 2 & 4 & 1 & 1 & 0 & 1 & 5 & 2 & & 0 & 8 & 3 & 5 & 0 & 0 & 7 & 3 & 3 & 2 & 0 & 2 & 3 & 4 & 2 \\
\hline $4 \mathrm{HR}$ & · & 3. & 1. & 5. & 7. & . & 2. & 8. & 6. & 5 & $\cdot$ & . & 5. & 5. & 0 & . & 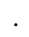 & 8. & 2. & 1. & & & 1. & 3. & 2. \\
\hline & 6 & 1 & 0 & 4 & 9 & 0 & 2 & 5 & 9 & & 0 & 8 & 3 & 9 & & 6 & 0 & 3 & 5 & 7 & 0 & 1 & 3 & 8 & 9 \\
\hline
\end{tabular}

Religion -wise CSR's understanding (Likert scale percentile)

Table 6 shows the trends and tendencies of overall respondents based on religious beliefs and affiliation. As discussed earlier, Buddhism, Hinduism and Islam are the prominent religions in South Asia and majority of population follow these three religions. The results of Likert scale demonstrate almost similar momentum for all the seven CSR's dimensions among all the above-mentioned religions. Parallel to previous results, the tendencies of these three religions were found on scale- 3 and scale-4. Individually, Buddhists shows $37.80 \%$ and $38.30 \%$, Hinduism $36 \%$ and $39.60 \%$ and Islam shows $35.80 \%$ and $37.20 \%$ on scale- 3 and scale- 4 respectively. On average scale, the values of Buddhism, Hinduism and Islam on scale- 3 and scale- 4 are $38.10 \%, 37.80 \%$ and $36.50 \%$ respectively. These findings confirm that religious beliefs and inclinations are parallel among all the believers from different religions in this region. On the other hand, the respondents who follow the Christianity which is not the major religion in South Asia shows incomparable results. The trends of these respondents are widespread; ranging from scale-3 to scale-5. On average, Christianity has shown an average value of $32.20 \%$ with individual values of $25 \%, 43 \%$ and $28.60 \%$ on scale-3, scale- 4 and scale-5 respectively. Similarly, none of these students selected any CSR's dimension on scale-1; showing much sensitivity towards moral corporate activities and thus CSR. This unique tendency may be due to the reason that respondents in this survey who believe in Christianity are highly educated with $25 \%$ Master degree and $58.30 \%$ doctorate degree.

Table 6. CSR's pattern on the basis of religion

\begin{tabular}{|c|c|c|c|c|c|c|c|c|c|c|c|c|c|c|c|c|c|c|c|c|}
\hline \multirow{2}{*}{ 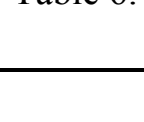 } & \multicolumn{5}{|c|}{ Buddhism } & \multicolumn{5}{|c|}{ Christianity } & \multicolumn{5}{|c|}{ Hinduism } & \multicolumn{5}{|c|}{ Islam } \\
\hline & 1 & 2 & 3 & 4 & 5 & 1 & 2 & 3 & 4 & 5 & 1 & 2 & 3 & 4 & 5 & 1 & 2 & 3 & 4 & 5 \\
\hline Accb & 0.0 & 3.4 & 32.2 & 42.4 & 22.0 & 0.0 & 0.0 & 0.0 & 58.3 & 41.7 & 0.0 & 8.8 & 30.0 & 43.4 & 17.8 & 2.3 & 4.5 & 28.1 & 44.7 & 20.4 \\
\hline Transp & 0.0 & 3.4 & 33.9 & 45.8 & 16.9 & 0.0 & 8.3 & 41.7 & 33.3 & 16.7 & 0.0 & 5.3 & 36.3 & 38.9 & 19.5 & 0.0 & 3.2 & 34.6 & 42.5 & 19.8 \\
\hline Eth beh & 0.0 & 8.5 & 40.7 & 30.5 & 20.3 & 0.0 & 0.0 & 33.3 & 33.4 & 33.3 & 0.0 & 4.4 & 36.3 & 42.5 & 16.8 & 2.3 & 5.3 & 37.1 & 32.6 & 22.7 \\
\hline Resp4stak & 0.0 & 6.8 & 40.7 & 39.0 & 13.5 & 0.0 & 8.3 & 33.3 & 16.7 & 41.7 & 0.0 & 0.9 & 36.3 & 43.3 & 19.5 & 0.8 & 8.3 & 31.1 & 44.7 & 15.2 \\
\hline Resp4RL & 1.7 & 5.1 & 40.7 & 32.2 & 20.3 & 0.0 & 0.0 & 8.3 & 58.3 & 33.4 & 0.0 & 9.7 & 33.6 & 42.5 & 14.2 & 0.0 & 3.8 & 39.4 & 37.9 & 18.9 \\
\hline Resp4intl & 0.0 & 3.4 & 45.8 & 33.9 & 16.9 & 0.0 & 8.3 & 33.3 & 58.4 & 0.0 & 0.9 & 7.1 & 34.5 & 30.1 & 27.4 & 0.8 & 5.3 & 39.4 & 31.8 & 22.8 \\
\hline Resp4HR & 1.7 & 5.1 & 30.5 & 44.1 & 18.6 & 0.0 & 0.0 & 25.0 & 41.7 & 33.3 & 0.0 & 5.3 & 45.1 & 36.3 & 13.3 & 0.8 & 14.4 & 40.9 & 26.5 & 17.5 \\
\hline
\end{tabular}

Comparison of regional CSR (Overall)

Figure 1 shows the collective trends of CSR dimensions in South Asia along with all individual six countries. It is reflected that overall trends of all CSR's dimensions are almost parallel; only with slight variations. Accountability has been categorized with $14.60 \%$, chased by transparency $(14.50 \%)$, ethical behavior, respect for stakeholders' interests and respect for international norms with identical values of $14.30 \%$, respect for rule of law and respect for human rights with values of $14.20 \%$ and $13.80 \%$ respectively. Similarly, a slight fluctuation has been observed in case of Bhutan (e.g., Transparency, Respect for stakeholder interest, Respect for rule of law and Respect for human rights) and Nepal (Accountability and Respect for human rights) while comparing the individual dimension with each target country. Rest of the four countries have comparable trends for each dimension except a bit variation in transparency in case of Bangladesh. In short, the results of this study did not find any visible variation among the selected countries in South Asian region. 
Figure 1. Regional CSR's comparison (overall)

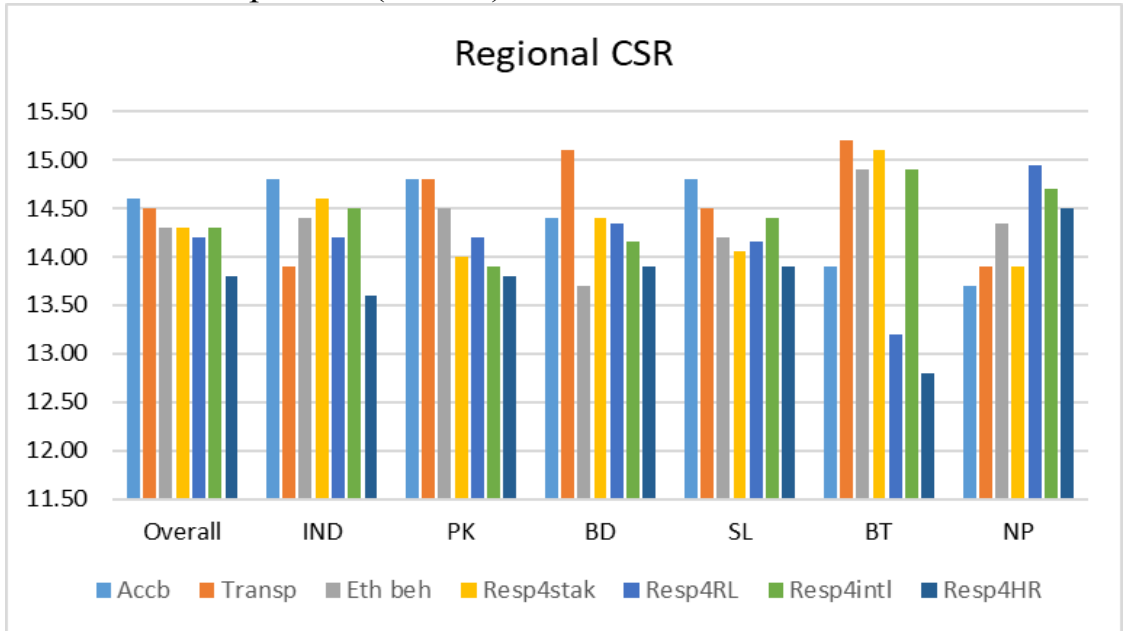

Individual CSR's dimension on the basis of regional educational level

Figure 2 shows the individual CSR dimension in target countries on the basis of educational level. Overall trends regarding every CSR dimension are leaded by master students and followed by PhDs in South Asian region. Similarly, regarding accountability, it is very easy to conclude that the tendency of this indicator was found among the master students followed by $\mathrm{PhDs}$ in all the individual countries except India and Bhutan. Surprisingly, Indian students with bachelor degree chase master degree students (both 66\%) in case of accountability dimension while students in Bhutan with SSC $(12.30 \%)$ have shown more inclination towards accountability than HSSC $(9.9 \%)$, bachelors $(9.9 \%)$ and $\mathrm{PhD}$ students $(6.2 \%)$. In same vein, for rest of the dimensions, the perception of Indian students having bachelor and master degree lined up (both; 65.40\%, 66.25\%, 64.75\%, 66.25\%, 65.80\% and $67 \%$ ) all the CSR indicators mentioned in this survey. India is the only country which has a steady and gradual tendencies from SSC to master but declined in PhD. Respondents from Pakistan and Bangladesh having higher education (Master and $\mathrm{PhD}$ ) show identical pattern for all CSR's dimensions. However, unusual diminution was observed in bachelor students when compare to other indicators within the same country or even with other countries. In simple words, bachelor students from Pakistan and Bangladesh have marked less importance to the CSR action in this research. Like other countries in the region, the tendency of CSR in Bhutan was also prioritized by master students; however, chased by both SSC HSSC. Bhutan is the only country where most educated people $(\mathrm{PhD}$ students) has given less importance to CSR actions as compare to other students' groups. Nepal has shown a gradual increase along with educational levels; from SSC to master, however most of the tendencies was observed in master and $\mathrm{PhD}$ students.

Figure 2. Individual CSR's dimension on the basis of education comparison (overall)
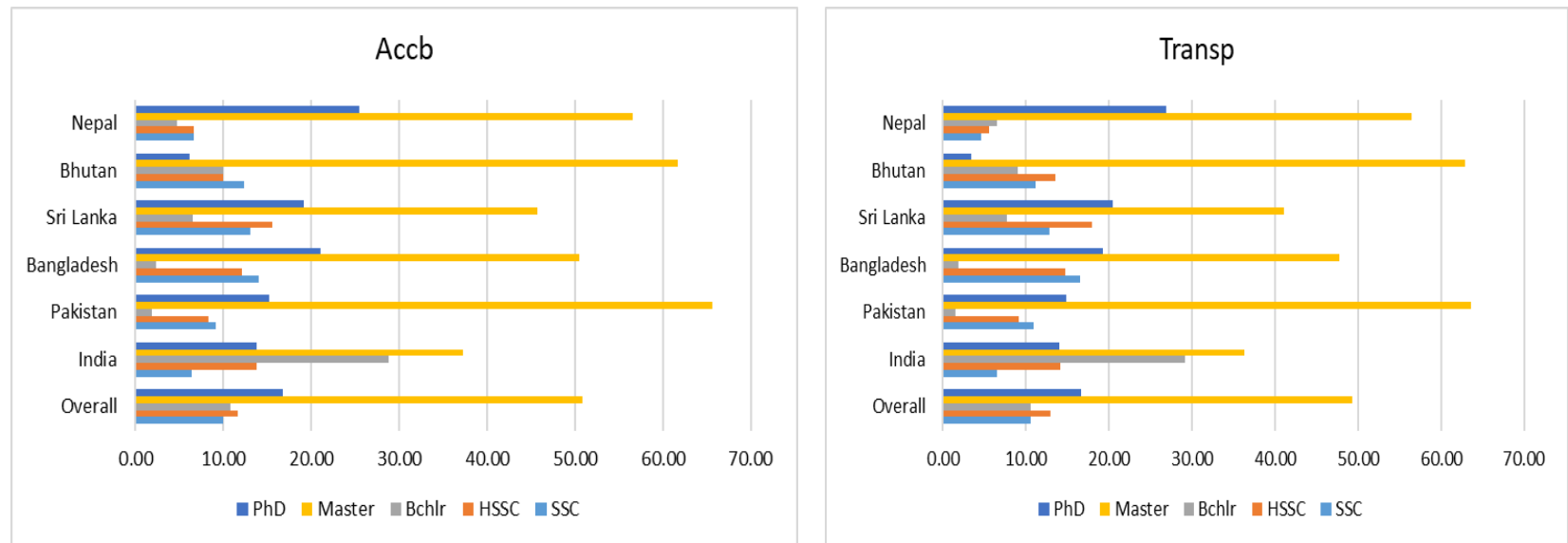

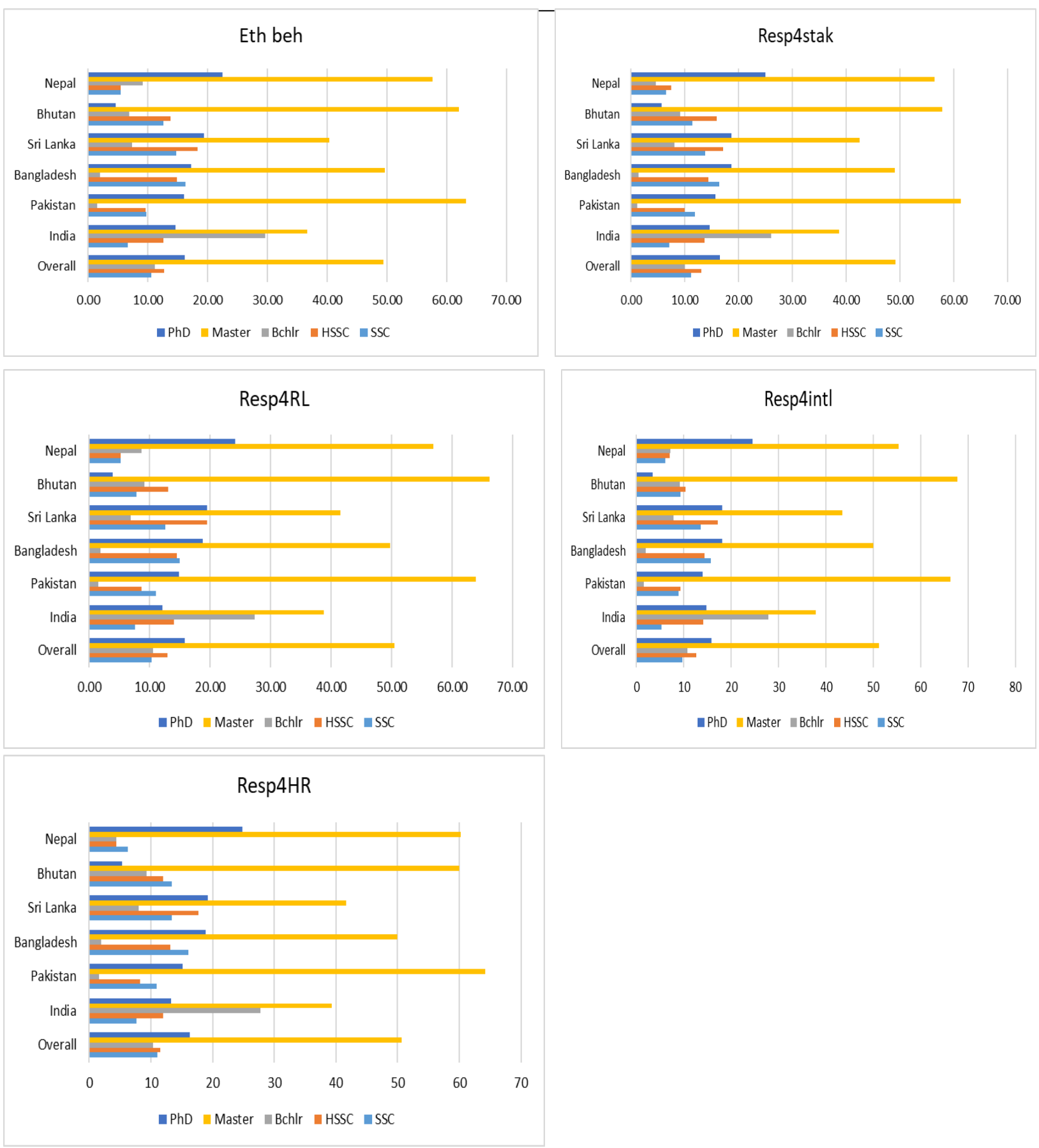

Social problems are neither new stories nor human misery has an end. In other words, if it's here (now), then it's everywhere (all the time). This is not an issue if a problem exists, but it's a big issue if nobody is trying to solve the problem. Vishwanath (2007) discovered that the understanding and execution of the concept of CSR is changing across various enterprises/sectors/industries and countries. CSR is not a universal phenomenon (Wang and Juslin, 2009) and corporations are unable to follow/implement the same rules and regulations globally (Mooij and Hofstede, 2010). Van den et al. (2014) identify the variation in CSR dynamics within one enterprise through applying universal policy in different countries and culture. From the findings of this study one can easily examine that the respondents have reacted more to specific CSR dimension in all the countries, which affirms not only the importance of this dimensions but the similar individual response across the borders. In spite of cross culture and multi-religious affiliations, the identical trends and patterns of CSR was observed among South Asian countries. These identical tendencies show that education system, course contents and teaching methods are almost the same within all the countries in South Asian region. Although, the academia is not much updated as compared to developed countries; however, students have basic 
understanding about the ethical activities and CSR. More importantly, these CSR dynamics identified by the students portray the new generation trends not only as a workforce but also other stakeholders; e.g., customers, suppliers, governmental officials or general community. In this regard, educational organizations are required to equip themselves with new teaching techniques and adopt innovative learning methods. With the help of teaching curriculum, education institutions can build an innovative learning environment for multi-disciplined students (especially researchers) to set together, discuss the real-world problems and find out the possible solutions. General public living within influential institutional environment, as in the case of developed world, are more inclined towards conducting ethical and CSR activities. This happens due to the reason that the personal behavior of general public in developed society are shaped congenitally by these institutional expectations, which is also claimed by Purcell et al. (2017). The motive of education institutions is to equip the future generation for upcoming challenges (e.g., social, economic, legal). Unfortunately, even in this era, most of academia are lacking the resources and skills to chase and tackle the modern challenges (Cao and Zhou., 2018; Bosman et al., 2019). Due to these obstacles, academia in developing countries is not obliged in full capacity to help their citizens. In addition, there might be loopholes in the course content or the understanding level of students in academia. Likierman (2004) criticized the education system by claiming that these institutions are working independently; without tackling the practical corporate problems and challenges.

In short, the revolution of academia and learning content play an important role to transform the priorities of students, which can then acknowledge the future problems and thus bring prosperity for the outside community within their domain of work. When compare the corporations and academia, it can be concluded that academia's CSR is just revolve around educational and learning dynamics, either theoretically or practically. CSR contents taught in academia urges the students' attitudes and perception for sustainable society (Holland, 2004). In this regard, the influential institutions (i.e., government, corporations, academia, etc.) should strive to explore the cause of problems and then focus on the proper solution with mutual consensus. Specific to CSR, as raised by business operation, they should take full responsibility (voluntarily) by scarifying their resources to eliminate or at least minimize its impact on society and make a safe planet for future generations. Academia should welcome the students and other stakeholders' opinions, as their perceptions convey exclusive and versatile outlooks to social development programs. The strong linkages between academia and society can enhance the progress of social sustainable programs (Cortese, 2003). Inter and intra universities collaboration is helpful in higher education, which influence the economic, environmental, cultural sustainability up to much extent and thus intellectual prosperity of overall society (Lozano, 2018). The involvement of students in solving such an important issue will motivate them which will positively affect learnings process. In the time of globalization and information technology, the requirements for business world are updating very promptly, therefore, the potential workforce should have the upgraded skills to cope any situation and thus making quick (but accurate) decision accordingly. In addition, it equips corporate managers to build a bond between corporation and society.

The findings of this study of the students' perception about the CSR knowledge are not much astonishing, as the learning process always explore new areas, beyond the thinking level of the general public. Initially, researchers have the same intuitions about the students' knowledge in the process of student's-academia engagement for this particular phenomenon. The results of this study also confirm the previous research conducted in other countries that educational institutes posture social and ethical values, which is not only beneficial for their personal career but also for the overall society. In such a situation, educational institutes, especially higher educations should aware how to best utilize the available resources to enhance 'reputation' and gain the state of 'monopoly' in education sector. The upcoming learning atmosphere are dynamics and the trends in academia are shifting very rapidly. New techniques are applied to involve Millennials in enterprises (e.g., CSR) and in academia (e.g., artificial intelligence and other technologies) (Ahmad, 2020). These countries have to do many things to be in the competition of achieving the quality standards in education, infrastructure, innovation, ethics. In simple words, the future classrooms will play the role of cross functional team, in which students from various major subjects' work/study together with the intentions to find the solution of specific problem with multi-disciplined approach. 


\section{Conclusion:}

These days, academia is under huge pressure to maintain updated course contents (innovative techniques) not only for students' satisfaction (learning process) but also to fulfil the corporate needs (problem solving). Such 'on the go' process (precise and accurate) can be achieved when there is a strong trilateral bond among educationist, corporations and government. In this modern era of information and communication technology, all the stakeholders (students, corporations, academia in this case) expect sophisticated, authentic but speedy learning and thus solutions to any problem. Generally, educational institutes are more concerned about the 'trending knowledge' and 'building core-values'. The incorporation of new concept through mutual consensus with the help of student's recognition and implementing their diverse opinions about single concept will open new gateways in education process. The results of such learning process will be judged and compare with other teaching's technique and corporate's framework. These speedy but accurate progress in learning process will endure to formulate innovative concepts and explore new areas for further research within academia, especially in the field of ethics and CSR. This study presents the ground level understandings from the potential workforce and one of the most important stakeholders' group about the widespread concept of CSR. This is suggested that more interim techniques should be applied to link the academic brain with the policy makers and other corporate managers to work together for the prosperity of human development, domestically, nationally and internationally. Cultural standards influence individual's social and ethical values and thus CSR actions. Therefore, the variation in cultural and institutional dynamics cause the differentiation in CSR perception. Personal or individual perspectives moral values institute corporate's ethical strategies which further execute guidelines for formulating and implementing CSR activities. Villanova et. al (2009) suggested that CSR operation is acting as a teaching technique for a corporation in which they learn many things about corporate governance and dealing outside community. These authors further added that a corporation can increase financial performance by involvement in marketplace, vision, community relations, workplace, and accountability. Learning process affect the human behavior in many aspects. In this regard, the higher education should not only upgrade their teaching method but also the course content in order to build the capacity of their potential workforce to resolve any problem in future.

Like other corporations, academia also confronts number of internal (financial constraints and staff/students' unwillingness) and external (legal and political systems) challenges. In spite of these obstacles, academia should try their level best to prevail CSR's culture within the campus premises. At least, they are liable to bring positive changes in learning process which are beneficials for the social development. These efforts will ultimately build/enhance academic reputation which will attract more motivated staff and bright students in future and thus governmental as well corporate grants. The results of this study are also important for international agencies, government and nongovernmental organizations and other relevant institutions to understand the basic 'know how' of customized CSR approach across the countries. More specific, with the help of potential workforce and decision makers, this study offers a comprehensive understanding and the specific trends of the ethical standards and CSR for future. Other researchers should examine the combine effect of government, academia and corporations. They should compare the inter and intra culture impact of every individual actor and explore their constrains of execution or avoiding CSR process. These investigations will sum up the overall gap that resist the CSR operation within given context. Such type of analyses is more important in developing countries; the reason is that government has given free hand to corporations whether to implement or not the CSR activities (voluntarily). In addition, in case of mandatory CSR guidelines, the impact of pre- and post-regulations should be examined and the changes should be identified to measure the quality of legal system, power of local government and effectiveness of other law and enforcement agencies.

References

A. Lockett, J. Moon, W. Visser. (2006). Corporate social responsibility in management research: Focus, nature, salience and sources of influence. Journal of Management Studies, 43 (1),115-136.

A.B. Carroll. (1999). Corporate social responsibility: Evolution of definitional construct. Business and Society, 38 (3), 268-295.

Aguilera-Caracuel, J., Hurtado-Torres, N.E., Aragón-Correa, J.A. and Rugman, A.M. (2013), "Differentiated effects of formal and informal institutional distance between countries on the environmental performance of multinational enterprises", Journal of Business Research, Vol. 66 No. 12, pp. 26572665. 
Ahmad, T. (2020). Scenario based approach to re-imagining future of higher education which prepares students for the future of work", Higher Education, Skills and Work-based Learning, Vol. 10 No. 1, pp. 217 238.

Amran, A. and Haniffa, R. (2011), "Evidence in development of sustainability reporting: a case of a developing country", Business Strategy and the Environment, Vol. 20 No. 3, pp. 141-156.

Aryati, A.S., Sudiro, A., Hadiwidjaja, D. and Noermijati, N. (2018), "The influence of ethical leadership to deviant workplace behavior mediated by ethical climate and organizational commitment”, International Journal of Law and Management, Vol. 60 No. 2, pp. 233-249.

Baba-Abugre, J. (2014), "Managerial role in organizational CSR: empirical lessons from Ghana", Corporate Governance, Vol. 14 No. 7, pp. 104-119.

Bandura, A. (1971), Social Learning Theory, General Learning Press, New York, NY.

Bondy, K., Matten, D. and Moon, J. (2008), "Multinational corporation codes of conduct: Governance tools for corporate social responsibility? Corporate governance-an”, Corporate Governance: An International Review, Vol. 16 No. 4, pp. 294-311.

Bosman, L., Hammoud, A. and Arumugam, S. (2019), "Applying empathy-driven participatory research methods to higher education new degree development”, Information Discovery and Delivery, Vol. 47 No. 1, pp. 17-24.

Bowen, R.H. (1953), Social Responsibilities of the Businessman, Harper, New York, NY.

Brandi, C.A. (2017), "Sustainability standards and sustainable development - synergies and trade-offs of transnational governance”, Sustainable Development, Vol. 25 No. 1, pp. 25-34.

Cao, Z.P. and Zhou, M. (2018), "Research on the innovation and entrepreneurship education mode in colleges and universities based on entrepreneurial ecosystem theory", Educational Sciences: Theory and Practice, Vol. 18 No. 5, pp.

Chakrabarty, S. and Bass, A.E. (2015), "Comparing virtue, consequentialist, and deontological ethics-based corporate social responsibility: mitigating microfinance risk in institutional voids”, Journal of Business Ethics, Vol. 126 No. 3, pp. 487-512.

Cortese, A.D. (2003), "The critical role of higher education in creating a sustainable future", Planning for Higher Education, Vol. 31 No. 3, pp. 15-22.

De Guimarães, J.C.F., Severo, E.A., Nobrega, K.C. and Tondolo, V.A.G. (2019), “Antecedents of student retention: the influence of innovation and quality of teaching in Brazilian universities", International Journal of Innovation and Learning, Inderscience Enterprises Ltd., Vol. 26 No. 3, pp. 235-255.

Deegan, C. and Unerman, J. (2006), Financial Accounting Theory: European Edition, McGraw-Hill, Maidenhead.

El Akremi, A., Gond, J.-P., Swaen, V., De Roeck, K. and Igalens, J. (2018), "How do employees perceive corporate responsibility? Development and validation of a multidimensional corporate stakeholder responsibility scale", Journal of Management, Vol. 44 No. 2, pp. 619-657.

Findler, F., Schönherr, N., Lozano, R., Reider, D. and Martinuzzi, A. (2019), "The impacts of higher education institutions on sustainable development", International Journal of Sustainability in Higher Education, Vol. 20 No. 1, pp. 23-38.

Freeman RE. Strategic management: A stakeholder approach. New York: Cambridge University Press; 2010.

G. Hofstede, G.J. Hofstede, M. Minkov. (2010). Cultures et organisations: Nos programmations mentales Pearson, France.

G. van den Heuvel, J. Soeters, T. Gössling. (2014). Global business, global responsibilities: Corporate social responsibility orientations within a multinational bank. Business \& Society, 53 (3), 378-413.

G.H. Hofstede, G. Hofstede. (2001). Culture's consequences: Comparing values, behaviors, institutions and organizations across nations Sage.

Gao, Y. and He, W. (2018), "Corporate social responsibility and employee organizational citizenship behavior: the pivotal roles of ethical leadership and organizational justice”, Management Decision, Vol. 55 No. 2, pp. 294-309.

Giacalone, R.A. and Thompson, K.R. (2006), "Business ethics and social responsibility education: Shifting the worldview", Academy of Management Learning \& Education, Vol. 5 No. 3, pp. 266-277.

Godemann, J., Haertle, J., Herzig, C., \& Moon, J. (2014). United Nations supported principles for responsible management education: Purpose, progress and prospects. Journal of Cleaner Production, 62(1), 16-23.

Gomez, L. (2014). The importance of university social responsibility in Hispanic America: A responsible trend in developing countries. Critical Studies on Corporate Social Responsibility, Governance and Sustainability, 8, 241-268.

Grabner-Kra“uter, S., Breitenecker, R.J. and Tafolli, F. (2020), 'Exploring the relationship between employees' CSR perceptions and intention to emigrate: evidence from a developing country", Business Ethics: A European Review, Vol. 1, pp. 1-6.

Gray, S.J., Kang, T., Lin, Z. and Tang, Q. (2015), "Earnings management in Europe post IFRS: do cultural influences persist?”, Management International Review, Vol. 55 No. 6, pp. 827-856. 
H. Mehrdost. (2012). Strategies to promote social responsibility in cultural organisations. International Journal of Business and Social Science, 3 (6), 236-242.

Haddock-Millar, J., Sanyal, C. and Muller-Camen, M. (2016), "Green human resource management: a comparative qualitative case study of a United States multinational corporation", International Journal of Human Resource Management, Vol. 27 No. 2, pp. 192-211.

Hahn, T.; Pinkse, J.; Preuss, L.; Figge, F. Tensions in Corporate Sustainability: Towards an Integrative Framework. J. Bus. Ethics 2015, 127, 297-316.

Han, S., Kang, T., Salter, S. and Yoo, Y.K. (2010), "A cross-country study on the effects of national culture on earnings management”, Journal of International Business Studies, Vol. 41 No. 1, pp. 123-141.

Hardi, P. and Buti, K. (2012), "Corporate governance variables: lessons from a holistic approach to CentralEastern european practice", Corporate Governance: The International Journal of Business in Society, Vol. 12 No. 1, pp. 101-117.

Hillenbrand, C., Money, K. and Ghobadian, A. (2013), "Unpacking the mechanism by which corporate social responsibility impacts stakeholder relationships", British Journal of Management, Vol. 24, pp. 127-146.

Hofstede G. Cultural constraints in management theories. Acad Manag Exec 1993; 7(1): 81-94.

Hofstede G. Cultures and organization: Software of the mind. London: McGraw-Hill; 1991.

Holland, L. Experiences from a student program designed to examine the role of accountant in corporate social responsibility (CSR). Int. J. Sustain. High. Educ. 2004, 5, 404-416.

Jha, C. and Panda, B. (2017), "Individualism and corruption: a cross-country analysis", Economic Papers: A Journal of Applied Economics and Policy, Vol. 36 No. 1, pp. 60-74.

Kanagaretnam, K., Lim, C. and Lobo, G. (2014), "Influence of national culture on accounting conservatism and risk-taking in the banking industry",The Accounting Review, Vol. 89 No. 3, pp. 1115-1149.

Khan, M., Lockhart, J. and Bathurst, R. (2020), "A multi-level institutional perspective of corporate social responsibility reporting: a mixed-method study", Journal of Cleaner Production, Vol. 265, pp. 1-14.

Lages LF, Fernandes JC. The SERPVAL scale: a multi-item instrument for measuring service personal values. J Bus Res, Elsevier 2005; 58(11):1562-72.

Likierman, A. (2004), “Key note speech: ideas and practice: why 'academic' should mean 'irrelevant", Fourth International Conference of the Performance Measurement Association, Performance Measurement Association, Edinburgh.

Lozano, R. (2018), "Proposing a definition and a framework of organizational sustainability: a review of efforts and a survey of approaches to change", Sustainability, Vol. 10 No. 4, pp. 11-57.

M. Blowfield, A. Murray. (2008). Corporate responsibility - A critical introduction, Oxford, Oxford University.

Mehta, S.R. (2011). Corporate social responsibility (CSR) and universities: Towards an integrative approach. International Journal of Social Science and Humanity, 1(4), 300-304.

Mele D. Not only Stakeholder Interests. The Firm Oriented toward the Common Good. Notre Dame: University of Notre Dame Press; 2002.

Mithani, M.A. (2017), "Liability of foreignness, natural disasters, and corporate philanthropy", Journal of International Business Studies, Vol. 48 No. 8.

Mooij, M. and Hofstede, G. (2010), "The Hofstede model applications to global branding and advertising strategy and research", International Journal of Advertising, Vol. 29 No. 1, pp. 85-110.

Ng, T.W., Yam, K.C. and Aguinis, H. (2019), "Employee perceptions of corporate social responsibility: effects on pride, embeddedness, and turnover", Personnel Psychology, Vol. 72 No. 1, pp. 107-137.

Oliver, C. (1997), "Sustainable competitive advantage: combining institutional and resource-based views", Strategic Management Journal, Vol. 18 No. 9, pp. 697-713.

Osagie, E.R., Wesselink, R., Blok, V., Lans, T. and Mulder, M. (2016). Individual competencies for corporate social responsibility: a literature and practice perspective. Journal of Business Ethics, 135 (2), 233-252.

Peterson, D.K. (2002), "Deviant workplace behaviour and the organization's ethical climate", Journal of Business and Psychology, Vol. 17 No. 1, pp. 47-61.

Purcell, W.M., Sharp, L. and Chahine, T. (2017), "New governance models for entrepreneurial universities: a conceptual framework", Academic Proceedings of the 2017 University-Industry Engagement Conference: From Best Practice to Next Practice - Asia-Pacific Opportunities and Perspectives, 25-6, pp. 19-29.

Purser RE, Park C,Montuori A. Limits to anthropocentrism: Toward an ecocentric organization paradigm. The Acad Manag Rev 1995; 20(4): 1053-89.

R. Lozano (2006). Incorporation and institutionalization of SD into universities: breaking through barriers to change. Journal of Cleaner Production, 14 (9-11), pp. 787-796.

Sapolsky, R. (2017), Behave: The Biology of Humans at our Best and Worst, Bodley Head, London.

Savageau, A.E. (2013), "Let's get personal: making sustainability tangible to students", International Journal of Sustainability in Higher Education, Vol. 14 No. 1, pp. 15-24.

Schneider, S.C., Zollo, M. and Manocha, R. (2010), "Developing socially responsible behaviour in managers", Journal of Corporate Citizenship, Vol. 39, pp. 21-40. 
Sorour, M.K., Boadu, M. and Soobaroyen, T. (2020), "The role of corporate social responsibility in organisational identity communication, co-creation and orientation”, Journal of Business Ethics, pp. 120 ,

Stechemesser, K.; Guenther, E. Carbon accounting: A systematic literature review. J. Clean. Prod. 2012, 36, 1738.

Suchman, M.C. (1995), "Managing legitimacy: strategic and institutional approaches", Academy of Management Review, Vol. 20 No. 3, pp. 571-610.

Uddin, S., Siddiqui, J. and Islam, M.A. (2018), "Corporate social responsibility disclosures, traditionalism and politics: a story from a traditional setting”, Journal of Business Ethics, Vol. 151 No. 2, pp. 409-428.

United Nations General Assembly (2015), "Transforming our world: the 2030 agenda for sustainable development", 25 September, available at: www.un.org/ga/search/view_doc.asp?symbol=A/ RES/70/1\&Lang=E (accessed 17 July 2020).

Vveinhardt, J. \& Andriukaitiene, R. (2015). Questionnaire verification of prevention of mobbing/ bullying as a psychosocial stressor when implementing CSR. Problems and Perspectives in Management, 13 (2), 5770.

Waddock, S. (2006), "Forging a path for ethics and business in society", Academy of Management Learning \& Education, Vol. 5 No. 3, pp. 334-345.

Wang, L. and Juslin, H. (2009), "The impact of Chinese culture on corporate social responsibility: the harmony approach", Journal of Business Ethics, Vol. 88 No. 3, pp. 433-451.

Wettstein, F. (2010), "The duty to protect: Corporate complicity, political responsibility, and human rights advocacy", Journal of Business Ethics, Vol. 96 No. 1, pp. 33-47.

World Commission on Environment and Development. Our Common Future. Oxford: wyww Oxford University Press; 1987.

Xiao, Y., Norris, C.B., Lenzen, M., Norris, G. and Murray, J. (2017). How social footprints of nations can assist in achieving the sustainable development goals. Ecological Economics, Vol. 135, 55-65. 